\title{
English Classroom Anxiety Status Quo and Countermeasure Analysis of Students in Higher Vocational and Technical Colleges
}

\author{
Xiaofang Tian \\ Tianjin Vocational Institute, Tianjin, 300410, China
}

\begin{abstract}
Keywords: Students in Higher Vocational and Technical Colleges; Language Classroom Anxiety Scale; solutions
\end{abstract}

\begin{abstract}
Classroom Anxiety, as a critical variable in learning English, has always affected learners. Due to weakness of basic knowledge of students in Higher Vocational and Technical Colleges (hereinafter referred to as students), they have a psychological fear of learning English. This paper conducts an empirical approach of students, aiming at understand and master the students' English learning anxiety status quo and puts forward solutions for anxiety problems based on Language Classroom Anxiety Scale prepared by Horwitz together with other people.
\end{abstract}

\section{Introduction}

With the coming of the information era and the popularization of higher education, many scholars began to focus on individual differences on an emotional basis. English learning anxiety, one of key emotional factors, is considered as a key obstacle to learning English and has a significant impact on English learning. Due to weakness of basic knowledge of Students in Higher Vocational and Technical Colleges (hereinafter referred to as students), they have a psychological fear of learning English. Therefore, it is necessary to study and discuss English classroom anxiety of students.

\section{Definition of anxiety and related research}

The concept of language Anxiety was first proposed by American psychologist Horwitz in 1986. He believes that language anxiety has relationship with classroom learning and will be existed in whole learning process of language learner. Macintyre stated that foreign language anxiety is stress and other negative emotions generated from listening, speaking and learning scenarios in 1994.

Horwitz together with other people prepared FLCAS in 1986 and indicated that there is a negative relationship between students' anxiety levels and student learning effect through the survey statistics analysis. After that, this scale is widely used and verified and proved by many scholars. According to Macintyre \& Gardaner in 1994, taking 97 students in learning French as research sample, it showed that the students with high degree of anxiety are not good at express their views and have inclination to underestimate their own abilities, which indicated that there is a negative relationship between their learning anxiety and learning effect. In 1994, Aida took students in learning Japanese as object, which showed that the key factors of foreign language anxiety are communication apprehension and fear of negative evaluation.

In 1996, Zhang Baoyan conducted a questionnaire survey of students in Taiwan and found that presence of anxiety conditions in their learning has no relationship with learning effect. Taking Chinese university students as object, Wang Caikang found that the scale has good reliability. The students' anxiety has negative relations with CET-4 scores.

All above study was conducted with undergraduate student as object, while there are relatively few studies on students in Higher Vocational and Technical Colleges. Higher vocational education is key part of higher education. The students in Higher Vocational and Technical Colleges, a special group, have a weakness of basic knowledge of English. Based on this point, many scholars begin to focus on their learning English situation. This paper attempts to study English classroom anxiety status quo of students on an emotional basis and put forward solutions for this problem. I hope that this will provide a enlightenment for English teaching in Higher Vocational and Technical Colleges. 


\section{Experimental Design}

\subsection{Research problems:}

This paper mainly study classroom anxiety status quo and solutions of students in higher vocational and technical colleges, specifically, the classroom anxiety status quo of students and specific classification of classroom anxiety, the relationship with PRETCO-A scores and how to reduce classroom anxiety.

\subsection{Object:}

We take students enrolling in 2012 and 2013 as research object, involving accounting, logistics, glasses, instruments and other majors, via questionnaires sent randomly. The total number of questionnaire is 360, of which 350 were valid questionnaires. There are 217 girls and 132 boys. Of which, there are 192 students passed PRETCO-A.

\subsection{Research Tools:}

Based on FLCAS prepared by Horwitz together with other people, there are 33 topics in this research with Likert 5 form. Of which, 1 refers to strongly disagree, 2 refers to disagree, 3 refers to unconfirmed, 4 refers to agree and 5 refers to totally agree. The higher score of questionnaire indicates the higher English learning anxiety.

All the valid data of questionnaires will be recorded in Excel, and then we use SPSS19.0 statistical software to conduct factor analysis, reliability analysis, descriptive statistical analysis and related analysis.

\subsection{Experimental data analysis:}

KMO and Bartlett's Sphericity Test:

We conduct factor analysis in 33 topics of FLCAS and the results show that KMO value is 0.927>0.9 in KMO and Bartlett's Sphericity Test. In 1976, Kaiser believed that the data is very suitable for factor analysis.

According to the inflection point in scree plot of factor analysis, we conduct analysis on 4 key factors. Through analysis of topics included in 4 factors, we name Factor 1 as general English anxiety with 18 topics, Factor 2 as self-perception anxiety in English classroom with 5 topics, Factor 3 as communication apprehension with 4 topics and Factor 4 as fear of negative evaluation with 3 topics.

\subsubsection{Analyze Internal Consistency Reliability of Extraction Factor}

After the extraction of 4 factors, we conduct internal consistency reliability analysis on total items in scale. We can see that the Cronbach's Alpha coefficient value in this scale is 0.905, which indicates that this scale has high internal consistency reliability of this scale. The Foreign Language Classroom Anxiety Scale is suitable for vocational students.

\subsubsection{Descriptive Analysis of 4 Factors}

According to descriptive analysis of 4 factors, the score of general English anxiety is 4.94, followed by fear of negative evaluation with 4.67 mean values. The self-perception anxiety and communication apprehension got lower scores, 4.60 and 4.25 respectively.

\subsubsection{Descriptive Analysis of topics in the scale}

According to analysis of mean value and standard deviation of 4 factors, it is indicated that the top four topics in Factor 1, containing 18 topics totally, are Topic 25 I always worry about backward due to so fast of English class going and Topic 33 I feel nervous when the problems issued by teach that is not familiar to me, with mean value of 2.96. Top 20 I can feel my heartbeat when I was answer question, with mean value of 2.95. Top 10 I always worry that failed in English exam, but got a high scale, with mean value of 2.82. The results show that the difference of basic knowledge of student is large, many students feel anxious due to fast of English teaching and students feel anxious when they asked questions.

For Factor 2 self-perception anxiety, Topic 5 I do not mind more English classes, with mean value of 2.82 that is highest score. The result indicates that even though student has anxiety in English class, they like English class. It is also indicated that students has identity of English to some extent.

According to Factor 3 communication apprehension, Topic 22 To be fully prepared in English 
class, I do not feel pressure, the highest score with mean value of 2.75. This explains that when students has fully prepared for English class, they do not feel anxious any more. Topic 18 I am very confident to speak in English class, with mean value of 2.47. This explains students fear to speak in English class.

According to Factor 4 fear of negative evaluation, Topic 13 I was embarrassed to answer questions in English class, highest score with mean value of 2.54. This indicates that students do not want to answer questions in English class. Topic 21 More learn made me confused in English exam, with mean value of 2.51. This shows that students feel confused in English exam and do not know how to deal with the exam.

2.4.4Correlation analyzes relationship between 4 factors of anxiety and PRETCO-A score

We make simple analyze relationship between 4 factors of anxiety and PRETCO-A score. According to table, correlation coefficient of general language anxiety and PRETCO-A score is -.132, $\mathrm{p}=0.013<0.05$; fear of negative evaluation and PRETCO-A score is -.187, $\mathrm{p}=0.000<0.01$; communication apprehension and PRETCO-A score is $-.110, \mathrm{p}=0.040<0.05$. All these results indicate that there is a negative correlation and the students with general language anxiety, fear of negative evaluation and communication apprehension has bad PRETCO-A score. The correlation coefficient of self-perception anxiety and PRETCO-A score is .170, $\mathrm{p}=0.001<0.01$ with positive correlation. The students with higher of self-perception anxiety gets higher PRETCO-A score. It indicates that they has high identity of English.

\subsection{Results Analysis:}

a) There are 33 Topics in Foreign Language Learning Anxiety Scale. Of which, there are 30 Topics related with English classroom anxiety. According to factor analysis of this scale, we extracted 4 factors, namely, general language anxiety, English class self-perception anxiety, communication apprehension and fear of negative evaluation. Among these 4 factors, the mean value of general language anxiety is 4.94 with highest value, followed by fear of negative evaluation with mean value of 4.67 . While the score of self-perception anxiety and communication apprehension is 4.60 and 4.25 respectively, lowest.

b) Top 4 of 18 Topics in Factor 1 is Topic 25, Topic 33, Topic 20, Topic 10. It shows that the difference of basic knowledge of students is large. Most students feel anxious due to teaching speed and questions from teacher. The mean value of Topic 5 in Factor 2 is 2.82 with highest position. It indicates that even though student has anxiety in English class, they like English class. It is also indicated that students has identity of English to some extent. The mean value of Topic 22 in Factor 3 is 2.75 with highest position. This explains that when students has fully prepared for English class, they do not feel anxious any more. Topic 18 in Factor 3 is followed with 2.47 mean values. This explains students fear to speak in English class. Topic 13 in Factor 4 is highest position with 2.54 mean values. This indicates that students do not want to answer questions in English class. Topic 21 More learn made me confused in English exam, with mean value of 2.51. This shows that students feel confused in English exam and do not know how to deal with the exam.

c) According to analyze relationship between 4 factors of anxiety and PRETCO-A score, correlation coefficient of general language anxiety and PRETCO-A score is -.132, $\mathrm{p}=0.013<0.05$; fear of negative evaluation and PRETCO-A score is -.187, $\mathrm{p}=0.000<0.01$; communication apprehension and PRETCO-A score is $-.110, \mathrm{p}=0.040<0.05$. All these results indicate that there is a negative correlation and the students with general language anxiety, fear of negative evaluation and communication apprehension has bad PRETCO-A score. The correlation coefficient of self-perception anxiety and PRETCO-A score is . $170, \mathrm{p}=0.001<0.01$ with positive correlation. The students with higher of self-perception anxiety gets higher PRETCO-A score. It indicates that they has high identity of English.

\section{Solutions for English Learning Anxiety}

According to analysis result, teachers shall update teaching philosophy, reform teaching methods and teaching evaluation method, adopt emotional teaching method and focus on language output so 
that it can reduce classroom learning anxiety.

1) Use information technology tools to reduce students' classroom anxiety

Today is highly developed information age. English class shall adopt information technology tools and methods, such as multimedia teaching, take advantage of sound lab to teach listening and speaking, BB platform, encourage students to submit assignments, discussion and interact with the teacher by BB platform, which could ease the students' classroom anxiety.

2) Positively Emotional communication with students,

According to research, even though student has anxiety in English class, they like English class. It is also indicated that students has identity of English to some extent. When students has fully prepared for English class, they do not feel anxious any more. Based on the above points, teachers shall conduct emotional education properly and communication with students to understand confusion and problems of English learning. The teachers shall use more vocabulary like praise when students in the group conversation, answer questions.

3) Adopt project teaching method in classroom; adopt cooperative learning approach to reduce students' classroom anxiety

For students in Higher Vocational and Technical Colleges, they have high English class anxiety. Among 4 Factors, the mean value of general language anxiety is highest, followed by fear of negative evaluation. The score of English class self-perception anxiety and communication apprehension is lowest. Therefore, the teachers can adopt project teaching method. That is to say, the teacher can divided each unit into several projects according to theme, and then let students in small groups to study. On the one hand, it can improve students' interest in learning English. According to tasks, students can collect materials by their interest and share results with other classmates. On the other hand, team members can consult and communicate with each other to avoid phenomenon like by teacher or ask teacher. So the classroom anxiety decreased.

4) Reform teaching evaluation methods

The study shows that students feel confused in English exam and do not know how to deal with the exam. Hence, teachers shall combine formative evaluation with summative assessment to carry out multi-faceted evaluation of the students. Of which, it shall focus on formative evaluation. Teachers must try their best to exert students' principal action through establishment of students' file. For example, teachers let students to accomplish self-assessment and mutual evaluation for their team or other teams, and then teachers give a comment.

5) Develop and enrich students' second class and culture students' cultural identity

According to simple research, we can know that there is positive correlation between self-perception anxiety and PRETCO-A score. The students with higher of self-perception anxiety gets higher PRETCO-A score. It indicates that they have high English identity. English classroom time is limited. In order to develop students' English identity, it must be extended first class and develop second class. Students shall be encouraged to participate in English Club, English culture festival, English speaking competition and select elective course related with English culture, such as Culture of English-speaking Countries, Appreciation of Western Movies and so on to enhance understanding and mastery the culture of English-speaking countries.

\section{References}

[1] Aida, Y. Examination of Horwitz and Cope's Construct of Foreign Language Anxiety: The Case of Students of Japanese[J]. The Modern Language Journal, 1994 ,78(2).

[2] Horwitz E.K., Horwitz M.B. \& Cope J. Foreign Language Classroom Anxiety [J]. Modern Language Journal, 198670 (2).

[3] Macintyre P. D. \& Gardner R.C. The Subtle Effects of Language Anxiety on Cognitive Processing in the Second Language [J]. Language Learning, 1994, 44.

[4] Wang Caikang. The Adaptation and Validation of the Foreign Language Classroom Anxiety Scale When Applied to Chinese College Students [J] Psychological Science, 2003 (2).

[5] Zhang Baoyan. A Study of Anxiety in Chinese EFL Learners[J]. Teaching and Research (Taipei), 1996 (18). 